\title{
Female Contraception in the Coming Years
}

\author{
CASPI ELIAHU \\ Tarnesby - Tarnowski Chair for Family Planning and Fertility Regulation, Obstetrics and Gynecology, \\ Sackler School of Medicine, Tel-Aviv University, Tel-Aviv, Israel
}

(Received 16 November 1998)

At present there is a large variety of quite effective contraceptives. When properly used by all fertile couples in order to space births and regulate fertility, especially in the developing countries where more than $85 \%$ of all births are taking place, the population growth could be limited to levels corresponding to the available world resources.

There is no doubt that the key to the population problem depends on the extent of fertility decline, since a significant increase in mortality in the near future is very unlikely. Unfortunately, acceptable birth rate is far from being reached because contraceptive use is restricted due to lack of compliance, troublesome side effects, high cost, reduced availability, unsolved logistic problems in addition to cultural, religious, ethical and political obstacles.

The scope of this presentation is to review the recent scientific and clinical research in the field of female contraceptives, which have some promise of being more acceptable for providers and users in the near future. The stress is on female contraceptives since even in western societies contraception is still considered a female concern.

\section{CONTRACEPTIVES AND SEXUALLY TRANSMITTED DISEASES}

Several contraceptive methods have been associated with altered rates of transmission of sexually transmitted disease (STD). Barrier contraceptive users (condoms, diaphragms, spermacides) have generally lower prevalence rates of STD than individuals using other forms of contraception, or no contraception [1]. In view of the AIDS epidemic it is hoped that improved barrier methods and spermicides will be effective in reducing the sexual transmission of Human Immunodeficiency Virus type I (HIV-I), the virus thought to cause AIDS. White blood cells infected with the AIDS virus are present in the semen and in lower quantity in the seminal plasma of infected men as well as in the cervix, vagina and mainly in the menstrual blood of infected women.

It is believed that condom use is protective to a certain extent against HIV-I transmission but the exact magnitude of such protection is unknown [2]. The present quality of male condoms is far from 
satisfactory with respect to their resistance to breakage and leakage of AIDS viruses. There is a continuous search for better male condoms. Recently a female condom has become available [3]. This is a pliable polyurethane or latex pouch inserted as lining to the whole vaginal surface. The advantage of this female condom is that the female protects herself by an efficacious and safe barrier to STD, mainly AIDS. Because of the high cost and rather low compliance, the female condom will probably not be a significant addition to contraception in the developing countries.

Spermicides consist of a carrier and an active sperm-killing agent. Various spermicides are used mainly as creams, suppositories, foam and sponges. The agents most generally considered safe and effective are the non-ionic surfactant nonoxynol-9, octoxynol-9 and benzalkonium chloride. The spermicide can be used alone but commonly in combination with condom, diaphragm, sponge or cervical caps. Although these spermicides are associated with a certain degree of protection against STD and they are known to inactivate HIV-1 in vitro and in vivo in animal models, a certain concern has been raised about potential genital irritation associated with spermicide use, an irritation which might enhance tissue access for HIV-1. The impact of such a concern is quite profound, resulting in a discount of the value of such spermicides as a part of contraceptives with potential protection against HIV-1 infection [4]. Probably the continuous research in this field will result in new nonirritant spermicides which are effective against STD and AIDS and reliable contraceptives as well.

\section{Female Sterilization}

Female sterilization by tubal blockage is one of the most popular methods of contraception in the United States and in many other countries. The drawback of this method is its irreversibility. A non-negligible percentage of women have a second thought years after and desire a reversal of sterilization.
In the meantime temporary tubal blockage by removable plugs has not achieved reliability and safe restoration of fertility afterwards. Female sterilization will probably remain a widespread permanent method of contraception for many years.

\section{Intra-uterine Devices (IUDs)}

Since the incorporation of copper or progestagens in the IUD, there have been no new devices. The IUD is still and will remain a foreign body in the uterine cavity with infectious and bleeding side effects which limit their use for a selected group of women only.

\section{Hormonal Contraceptives}

Since the revolutionary introduction of the "pill" some 30 years ago it has changed significantly with respect to the dosage of the two hormonal constituents, progestagen and estrogen which are currently reduced to very low doses without affecting its very high contraception. In addition, new progestagens, gestodene, norgestimate and desogestrel in low dose were also introduced. However, the multitude of side effects of the pill, most of them of minor degree, are more widely stressed than the important beneficial effects, in addition to the fact that this is the most effective contraception.

A few weeks ago a worldwide panic was created by announcement from the United Kingdom Committee on Safety of Medicine (CSM) that the pill containing the new progestagens gestodene and desogestrel are associated with a two-fold increased risk of thromboembolism and pulmonary embolism compared to the pill with older (second generation) progestagens. This surprising announcement was based on studies not yet published nor evaluated properly. Nevertheless, the effect of such a statement is already felt and is certainly very harsh against the use of the pill.

The solution to the problem of the side effects of current hormonal contraception, be it the conventional pill, the minipill containing progestagen only, or even the injectable or implantable hormones, is in the elucidation of subcellular and molecular 
mechanism of steroid action, mainly the understanding of steroids receptor structures and function. Currently, steroidal molecules display a multiplicity of actions some of which are beneficial and some are disturbing. Today it is possible to isolate steroid receptors for various tissues and expose them to the effects of different molecules, not only steroids, that could bind to specific receptors activating only the desired effects avoiding any other unwanted side effects.

In different species including man, a diffusible substance inducing meiosis (meiosis-activating sterols (MAS)) was isolated from the gonads, ovaries and testes. Two closely related substances C 29 sterols were synthesized by a group led by Byskov from Copenhagen [5]. Those sterols induce a resumption of meiosis in oocytes. Substances inactivating those sterols may prove to be a means of non-hormonal contraception by preventing meiosis in the oocyte so that fertilization is impossible without any hormonal disturbances.

However, the time and funds necessary for animal studies and clinical trials in the human are such that it is unlikely that in the coming years we will see this entirely new non-hormonal pill.

One way of improving the availability of the pill is to get it over-the-counter without a physicians prescription. The pill is not toxic, non-addictive and the dose does not need to be adjusted. Yet there is a great resistance from physicians and women to overthe-counter pill.

A recent Gallup Poll commissioned by the American College of Obstetricians and Gynecologists suggests that over-the-counter pill is a long way off [6]. The majority of women in USA still believe that the pill is too dangerous to be taken without medical supervision. Proper understanding of the risks and benefits of the pill will change this attitude so that over-the-counter availability is possible and will certainly promote their use.

\section{Emergency Contraception}

In cases of accidental failed contraception use or no contraception at all with coital exposure, an emergency contraception is obviously in need, mainly for adolescents who frequently do not use contraception when they start sexual experimentation. Emergency contraception means avoiding pregnancy after unprotected intercourse at the ovulatory period. The best method for emergency contraception in respect of safety, side effects, reliability and patient compliance is mefipristone, an anti-progesterone competing with progesterone at the receptor level mainly in the endometrium, nullifying the effect of endogenous progesterone. One pill containing $600 \mathrm{mg}$ of mefipristone given at the end of the menstrual cycle few days before menstruation will provoke luteolysis and uterine bleeding even in the presence of an early conceptus. In many clinical trials the mefipristone was effective in preventing pregnancy in $100 \%$ of the cases with unprotected intercourse [7]. The molecules of mefipristone were synthesized more than 10 years ago by Beaulieu in France and are used effectively and safely for medical abortion of very early pregnancies, so it is considered as an abortifacient and as such is not acceptable to many. Currently mefipristone is available in only three countries for induction of abortion. But it should be registered and made available in all countries for the sole indication of emergency contraception.

\section{Injectable Contraceptives}

Oral contraception necessitates the ingestion of a pill daily which can be inconvenient for many women. A once-a-month pill is not forseen even in the far horizon. But once-a-month injection of a combined estrogen and progestagen is available and already in use. Injectable contraceptives containing progestagens only, have been in existence for many years but they are long acting for a period of 2-6 months and are associated with very frequent bleeding irregularities. The monthly injection method fills a gap in the currently available technology - and fulfills many of the features of an ideal contraceptive as it is highly effective, simple to use, unrelated to coitus, needs little motivation and is relatively inexpensive [8]. 
The monthly injectable contraceptive most used is cyclofem containing $25 \mathrm{mg}$ of depomedroxyprogesterone acetate and $5 \mathrm{mg}$ of estradiol cypionate and the other one is mesigyna which includes $50 \mathrm{mg}$ norethisterone enantate and $5 \mathrm{mg}$ of estradiol valerate. Many other combinations are currently being experimented. It is estimated that more than two million women are using the present monthly injectable contraceptives and the projection is that this kind of contraceptive will be more in use in the coming years.

\section{The Hormonal Vaginal Ring}

A new form of hormonal contraception is the hormonal vaginal ring which is made of plastic material carrying progestagen alone or combined with estrogen slowly released during several months into the circulation through the vaginal epithelium. The most acceptable are the rings with a combination of progestagen and estrogen [9]. The subject inserts the ring in the vagina at the beginning of the cycle for a duration of 21 days, then it is removed for seven days after which it is replaced to begin the next cycle. The vaginal ring is being experimented for a while in some countries with a growing success. The majority of women mention its ease of use compared to the daily pill. There are still some problems that must be solved but it is probable that the vaginal ring will be approved and will gain widespread use.

\section{Hormonal Implants}

A method which is gaining more and more popularity is the hormonal implants. They are subdermal implants that release low, stable amounts of progestagens from silastic or other material for periods of months to several years.

The first in use was norplant made out of six capsules, containing levonorgestrel inserted surgically by local anesthesia under the skin on the inside of the upper arm for 5 years while releasing a constant contraceptive level of progestagen. However, there are many problems with those implants. There are frequent difficulties and complications of the insertion and more so with the removal after several years or earlier if reversibility is desired in addition to many other side effects mainly bleeding irregularities. For these reasons many clinicians fail to recommend the use of norplant. New implants are being developed that are simpler to use by reducing the number of rods from 6 to 2 (norplant 2) and by using new progestagens such as 3-keto-desogestrel and even a biodegradable implant not necessitating removal at all [10]. If removal of the implant is eliminated then one of the most problematic issues of the implantable hormonal contraceptives would be resolved. Moreover, biodegradable subdermal pellets of the size of a grain of rice are also being investigated. Fewer and degradable implants with new progestagens can be a new option for fertility regulation in the near future as more than three million women around the world are now using these implants.

\section{Birth Control Vaccines}

For two decades there has been an ongoing search for a vaccine against pregnancy with which women can be vaccinated and prevent pregnancy for a desirable period of time. Many vaccines are theoretically possible but only two are holding some promise. The first is a vaccine against the hormone human chorionic gonadotropin (HCG) produced by the fertilized egg just before implantation and the other is a vaccine against certain constituents unique to the sperm. Both HCG and the sperm are foreign to the female body and their neutralization is probably without a risk of an autoimmune reaction to other body tissues.

Anti-sperm antibodies produced by the vaccinated women preventing the union of the sperm with the egg might appease even the ardent pro-lifers since fertilization is prevented, thus such a vaccine cannot be considered as an abortifacient.

Vaccine against the three constituants found only in the sperm, the enzyme lactate dehydrogenose $\mathrm{C} 4$ [11], a glycoprotein SP-10 [12] and a protein $\mathrm{PH}-20$ [13] were tested in animals by producing antibodies in the female against those antigens with certain promising results in terms of reduced fertility. They 
are currently tested in non-human primates. They still have a very long way before they may be considered for trial in the human.

The vaccine against HCG is studied by two teams - one led by Talwer of India's National Institute of Immunology in Delhi and the other team led by Stevens from Ohio State University. These studies are advanced to stages of clinical trials in the human.

HCG is secreted by the blastocyst just before implantation and mainly by the early throphoblast at and after implantation acting as a luteotropic hormone on the corpus luteum to produce progesterone for the maintenance of pregnancy during the early stage. Antibodies against HCG will neutralize the luteotropic action resulting in regression of the corpus luteum and disruption of the peri-implantation embyro, leading to an apparently normal menstruation. In non-human primate immunity to HCG blocks fertility at a very early stage of pregnancy with no alteration in the menstrual cycle. Immunological neutralization of the specific $\beta$ subunit of the HCG molecule which is composed of the non-specific $\alpha$-subunit and the specific subunit has been shown to prevent or disrupt implantation in non-human primates. After toxicological studies in laboratory animals and baboons a phase-I clinical trial was conducted by the two groups on surgically sterilized women $[14,15]$. Potentially contraceptive levels of antibodies to HCG developed in all women with no important adverse reactions.

Phase-II studies on humans was conducted by the group led by Talwar in India on 148 fertile healthy young women [16]. They received different dosages of the vaccine by three injections at six week intervals with booster injections given subsequently. All women produced antibodies to HCG but only $80 \%$ generated titers over $50 \mathrm{ng} / \mathrm{ml}$. Of those only one pregnancy occurred during 1224 cycles while 26 pregnancies occurred among participants who had titers below the level of $50 \mathrm{ng} / \mathrm{ml}$. The response to the vaccine was reversible, antibodies titers declined in all cases in the absence of booster injections and some women became pregnant when antibody titers fell below $35 \mathrm{ng} / \mathrm{ml}$. This study has provided evidence for prevention of pregnancy in women by anti-HCG antibodies. The protective level of the antibodies is over $50 \mathrm{ng} / \mathrm{ml}$ and can be maintained by booster injections of the vaccine for the desired time after which fertility is restored. However a great deal of work is still necessary to make this vaccine a method for general use. The immune response must be improved, since in $20 \%$ of the subjects the level of the antibodies was below the protective level of $50 \mathrm{ng} /$ $\mathrm{ml}$. The present method requires the impractical multiple injections. A method of encapsulation of the vaccine in microspheres for a long-lasting antibody response must be found in order to reduce the number of injections. Such a vaccine cannot be expected to be ready for general use in the near future because of the need of very long toxicological studies in large scale.

The anti-abortionists and the so-called pro-lifers might consider the anti-HCG vaccine an early abortifacient since there can be a disruption of very early implanted fertilized egg. Such a view will certainly not be helpful in further scientific work on this anti-birth vaccine.

Since the pill and the IUD, we have had no entirely new type of female contraceptive in the last 20 years. Are we going to have one in the coming years? The answer to this question is probably affirmative if an effort of governments, private societies, pharmaceutical companies, scientists and educators is combined for the production of safe and reliable contraceptives.

\section{References}

[1] K.M. Stone, D.A. Grimes and L.S. Magder. Primary prevention of sexually transmitted disease. JAMA 255: $1763,1986$.

[2] E.N. Ngugi, F.A. Plummer et al. Prevention of transmission of HIV in Africa. Lancet 2: 887, 1988.

[3] D.E. Greydanus and D. Lonchamp. Contraception in the adolescent. Med. Clin. N. Amer. 74(5): 1205, 1990.

[4] M.E. Guinan. The risk of sexually transmitted disease in women. Proceedings of the U.S. FDA Obstetrics and Gynecology Devices Panel, Rockville MD, January 31st, 1992.

[5] A.G. Byskov, C.Y. Anderson, L. Nordholm et al. Chemical structure of sterols that activate oocyte meiosis. Nature 374: $559,1995$.

[6] D.A. Grims. Over-the-counter Oral Contraceptives. Obstet. Gynecol. Survery 50: 411, 1995. 
[7] A. Glasier. Emergency contraception. British J. Obstet. Gynecol. 100: 611, 1993.

[8] M.K. Tappozada. Existing one-a-month combined injectable contraceptives. Contraception 49: 293, 1994.

[9] S.A. Ballagh, D.R. Mishell et al. A contraceptive vaginal ring. Contraception 50: 517, 1994.

[10] P.D. Darney. Hormonal implants: Contraception for a new century. Am. J. Obstet. Gynecol. 170: 1536, 1994.

[11] E. Goldbery and J.A. Shelton. Immunosuppression of fertility by LDH-C1. In G.P. Talwar, (ed) Immunological Approaches to Contraception and Promotion of Fertility. New York, Plenum Press, pp. 219-230, 1986.

[12] J.C. Herr, C.J. Flickinger, N. Humyk et al. Biochemical and morphological characterization of the Intra-acrosomal antigen SP-10 from human sperm. Biol. Reprod. 42: 181, 1990.

[13] P. Primakoff, W. Lethrop and L. Woolman. Fully effective contraception in male and female guinea pigs immunized with the sperm protein PH-20. Nature 335: 543, 1988.

[14] W.R. Jones, S.J. Judd, R.M.Y. Ing et al. Phase I Clinical trial of a World Health Organization birth control vaccine. Lancet 2: 1295, 1988.

[15] G.P. Talwar, V. Hingorani, Kumars et al. Phase I clinical trials with three formulations of anti-human chorionic gonadatropin vaccine. Contraception 41: 301, 1990.

[16] G.P. Talwar, O.M. Singh, R. Pal et al. A vaccine that prevents pregnancy in women. Proc. Natl. Acad. Sci. USA 91: 8532,1994 


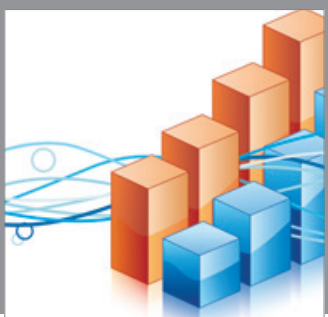

Advances in

Operations Research

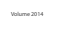

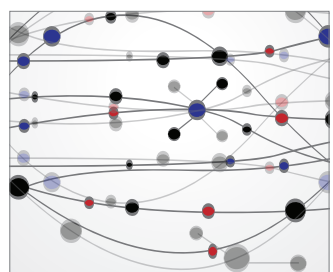

\section{The Scientific} World Journal
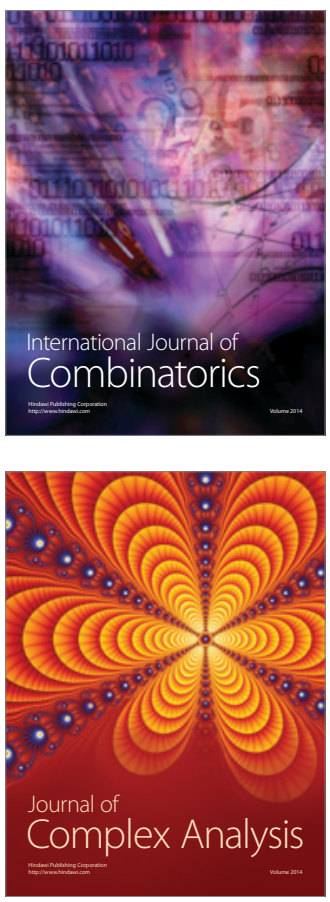

International Journal of

Mathematics and

Mathematical

Sciences
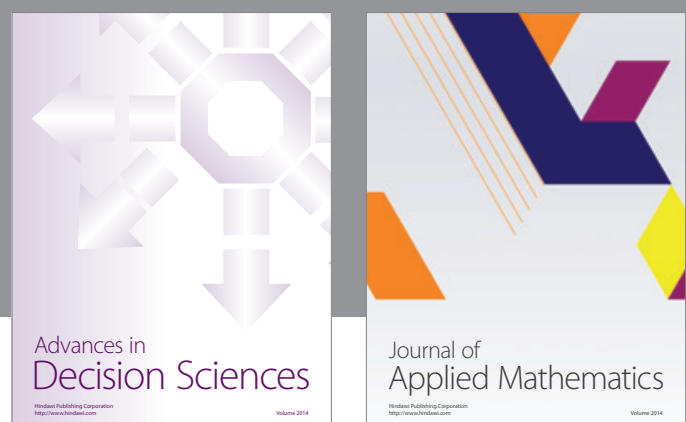

Journal of

Applied Mathematics
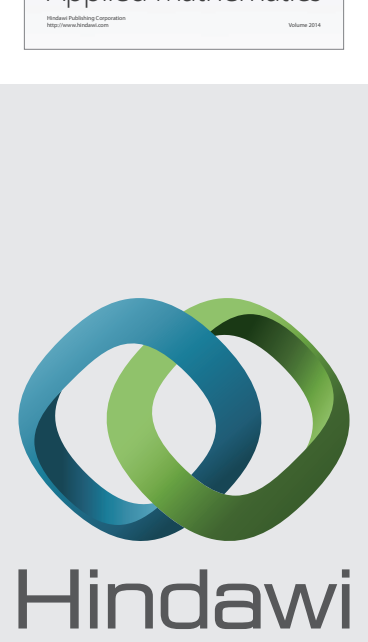

Submit your manuscripts at http://www.hindawi.com
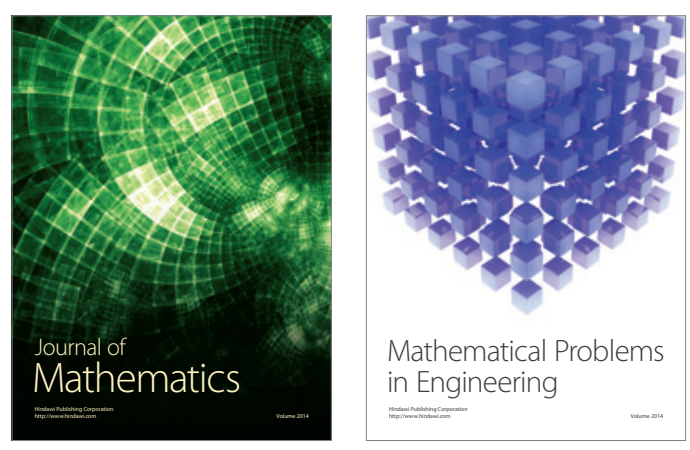

Mathematical Problems in Engineering
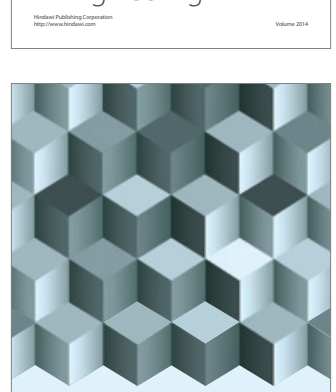

Journal of

Function Spaces
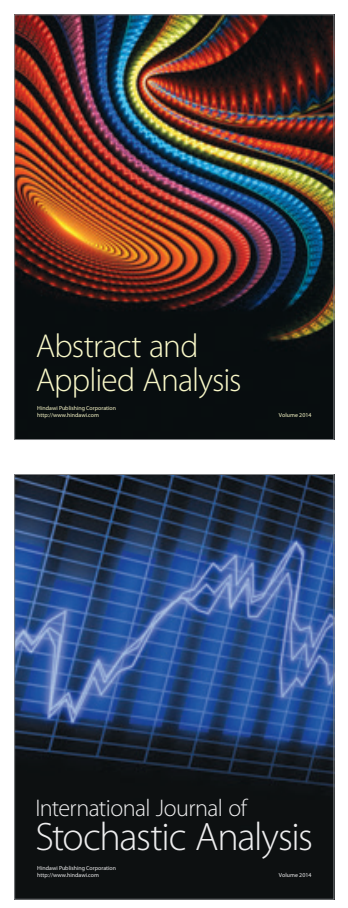

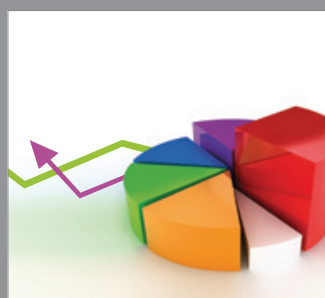

ournal of

Probability and Statistics

Promensencen
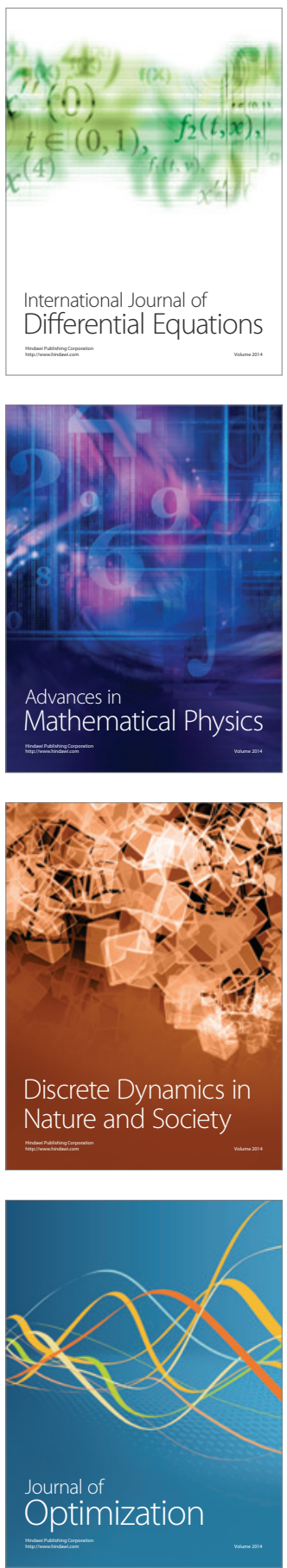